Review

\title{
Effects of biomechanical forces on the biological behavior of cancer stem cells
}

\author{
Bo Ren Tian, Wei Fan Lin, Yan Zhang ${ }^{\bowtie}$ \\ MOE Key Laboratory of Gene Function and Regulation, School of Life Sciences, Sun Yat-sen University, Guangzhou 510006, Guangdong, People's Republic of \\ China. \\ $\triangle$ Corresponding author: Yan Zhang, MOE Key Laboratory of Gene Function and Regulation, School of Life Sciences, Sun Yat-sen University, Guangzhou \\ 510006, Guangdong, People's Republic of China. Tel. \& Fax: 0086-2039332955; E-mail: zhang39@mail.sysu.edu.cn. \\ (c) The author(s). This is an open access article distributed under the terms of the Creative Commons Attribution License (https://creativecommons.org/licenses/by/4.0/). \\ See http://ivyspring.com/terms for full terms and conditions.
}

Received: 2021.03.26; Accepted: 2021.07.20; Published: 2021.08.08

\begin{abstract}
Cancer stem cells (CSCs), dynamic subsets of cancer cells, are responsible for malignant progression. The unique properties of CSCs, including self-renewal, differentiation, and malignancy, closely depend on the tumor microenvironment. Mechanical components in the microenvironment, including matrix stiffness, fluid shear stress, compression and tension stress, affect the fate of CSCs and further influence the cancer process. This paper reviews recent studies of mechanical components and CSCs, and further discusses the intrinsic correlation among them. Regulatory mechanisms of mechanical microenvironment, which act on CSCs, have great potential for clinical application and provide different perspectives to drugs and treatment design.
\end{abstract}

Key words: tumor microenvironment; cancer stem cell; matrix stiffness; shear stress; compression and tension

\section{Introduction}

Cancer is the second leading cause of death worldwide and poses a great threat to human life and health. A variety of treatments, including surgery, chemotherapy, radiation therapy, and moleculetargeted therapies, such as angiogenesis inhibitors, tyrosine kinase inhibitors, and monoclonal antibodies, have been widely deployed against cancer, yet the outcomes for patients, particularly those with the most aggressive cancers, remain mixed [1, 2]. Although many studies have been conducted on the tumorigenesis and metastasis of cancer, there are still various aspects not well understood.

Within cancer tissues, there are several dynamic subsets of cancer cells considered to be cancer stem cells (CSCs) or stem cell-like cancer cells $[3,4]$. CSCs are often identified with abundant expression of stem cell markers, long-term clonal proliferation, tumoriginecity, facilitating metastasis and resistance to chemotherapy. Since the first demonstration of the presence of CSCs in leukemia [5], the existence of CSCs has been successfully demonstrated in a variety of cancers [6-10]. Both clinical and experimental data indicate that CSCs can survive during chemotherapy and radiation therapy [11]. The existence of CSCs is a barrier that limits therapeutic effect [12], although CSCs may be dormant and quiescent for long periods of time [13]. Thorough studies on CSCs may offer theoretical guidance for cancer therapy in clinical practice.

Many studies have demonstrated that the microenvironment could regulate stem cell fate by providing biological conditions, including those that are cell-to-cell, cell- or non-cell factors, and mechanical stimuli [14-17], which showed that mechanical factors could affect stem cell proliferation, migration, differentiation, stemness maintenance, and other biological behaviors $[18,19]$. These mechanical components include matrix stiffness, fluid shear stress, cyclic stretching or compression, even gravity environments, or topological structures [20-22].

In recent years, the biomechanical microenvironment of cancer has attracted more attention [23]. Several studies have shown that the biomechanical microenvironment in solid tumors differs completely from that in surrounding tissues [24]. Throughout the process of cancer development, 
excessive and disordered cell proliferation will lead to abnormal development of the biomechanical microenvironment, including solid stress, increased tissue stiffness, and an abnormal interstitial fluid pressure (IFP) [25]. This special biomechanical microenvironment might play an important role in maintaining the survival of CSCs and cancerassociated cells [26]. For example, in the process of hematogenous metastasis, cancer cells leave the primary niche and enter the circulatory system with a unique biomechanical microenvironment. During the transition through the circulatory system, cancer cells are subjected to hemodynamic forces, immunological stress, and collisions with host cells, such as blood cells and the endothelial cells lining the vessel wall [27]. These biomechanical stressors could affect cancer cell fate and the ability to establish metastatic foci [28]. Moreover, all of these biomechanical stressors could affect CSCs stemness during cancer progress (Table $1)$.

\section{The biomechanical microenvironment in solid tumor}

\section{Matrix stiffness}

The biomechanical microenvironment in cancer tissue has three unique characteristics: solid stress caused by unregulated proliferation of cancer cells, increased extracellular matrix (ECM) stiffness, and abnormal IFP [26]. The increasing accumulation of ECM changes tissue density, which eventually leads to a gradual change in the tissue's stiffness [29]. It is generally believed that the stiffness of solid tumor is much higher than that of normal tissue [30]. For example, a normal mammary gland has a modulus of elasticity of less than $200 \mathrm{~Pa}$, while the tumor over 4 $\mathrm{kPa}$; normal liver tissue has a stiffness between 4 and $10 \mathrm{kPa}$, yet the stiffness of a liver cancer tends to be 20 to $50 \mathrm{kPa}$ or higher $[29,31]$. As osteosarcomas arise in the hardest tissue of the body, the dogma stating that solid tumors are macroscopically harder than the healthy tissue from which they originate does not apply in this case [32]. It was shown that osteosarcomas are markedly weaker and softer, exhibiting a step-by-step bone matrix reduction and degradation, indicative of sequential bone structural failures [33]. There are also differences in stiffness within tumors. In the interior of a solid tumor, different areas show distinct stiffness profiles, and the stiffness in the invasion frontier is much stiffer than that of the central area [34].

\section{Shear stress}

When cancer tissues enlarge to a certain size, they tend to be hypoxic. This could cause cancer cells or cancer-related cells to produce abnormal secretion of vascular endothelial growth factor (VEGF) or other angiogenic factors, causing disordered angiogenesis and lymphangiogenesis [35]. However, these neo-vessels are poorly functional, with irregular networks and high permeability [28]. Therefore, liquids and macromolecules are more likely to infiltrate the interspace, breaking the balance of osmotic pressure, resulting in elevated tumor IFP [36]. In solid tumors, the increasing number of lymphatic vessels around the tumor which is coupled with high IFP, leads to a rise in tumor fluid flux [37]. The IFP within solid tumors, although slower in flow rate compared with blood shear stress, still produces a certain fluid shear stress that can influence cell behavior (Fig. 1). In addition to the fluid shearing force, the flow of the interstitial fluid causes the concentration gradient of the solute molecules or signal molecules, and the concentration gradient is generated inside or outside the cell, contributing to signal transmission and the exchange of substances [26].

Table 1. Mechanical effects on CSCs

\begin{tabular}{|c|c|c|}
\hline Model & Mechanical environment & Outcome \\
\hline HCC culture on polyacrylamide gels [58] & Substrate stiffness: $6-16 \mathrm{kPa}$ & HCCs show higher stemness on the $16 \mathrm{kPa}$ substrate gels \\
\hline HCC culture on polyacrylamide gels [49] & Substrate stiffness: $1-10 \mathrm{kPa}$ & HCCs show higher stemness on $1 \mathrm{kPa}$ substrate gels \\
\hline $\begin{array}{l}\text { Breast cancer cell culture on polyacrylamide gels and hypoxic } \\
\text { environment [50] }\end{array}$ & Substrate stiffness: $0.13-4.02 \mathrm{kPa}$ & $\begin{array}{l}\text { Stiffness and hypoxic factors promote the development of } \\
\text { breast CSCs }\end{array}$ \\
\hline Colorectal cancer culture on Polyacrylamide gels [51] & Substrate stiffness: $2-20 \mathrm{kPa}$ & $\begin{array}{l}\text { HCT-116 cells show higher numbers of CSC markers with } \\
\text { increasing stiffness of gels }\end{array}$ \\
\hline Melanoma CSC culture on 3D fibrin gels [52] & Gel stiffness: $90-1050 \mathrm{~Pa}$ & $\begin{array}{l}\text { CSCs have a better ability to maintain stem cell } \\
\text { characteristics on a softer matrix stiffness }\end{array}$ \\
\hline $\begin{array}{l}\text { Ovarian carcinoma cell culture on a poly-HEMA-coated } \\
\text { microfluidic channel [59] }\end{array}$ & Shear stress: $0.002-0.02$ dyne $/ \mathrm{cm}^{2}$ & $\begin{array}{l}\text { Ovarian cancer cells acquired the expression of EMT and } \\
\text { CSC markers with } 0.02 \text { dyne } / \mathrm{cm}^{2} \text { shear stress }\end{array}$ \\
\hline $\begin{array}{l}\text { Breast cancer cell culture in a computational fluid dynamics } \\
\text { module [78] }\end{array}$ & Shear stress: $20-60$ dyne $/ \mathrm{cm}^{2}$ & $\begin{array}{l}\text { MCF7 cells show high numbers of CSC marker under } \\
\text { shear stress compared with a static state }\end{array}$ \\
\hline $\begin{array}{l}\text { Liver CSC culture on a parallel-plated flow chamber system } \\
\text { [84] }\end{array}$ & Shear stress: 2 dyne $/ \mathrm{cm}^{2}$ & $\begin{array}{l}\text { Liver CSC stemness is reduced under shear stress via the } \\
\text { Wnt/ } \beta \text {-catenin signalling pathway }\end{array}$ \\
\hline Tumor culture on a stress clamp [85] & Compressive stress: $5-10 \mathrm{kPa}$ & $\begin{array}{l}\text { Tumour sphere volume is reduced under compressive } \\
\text { stress }\end{array}$ \\
\hline
\end{tabular}




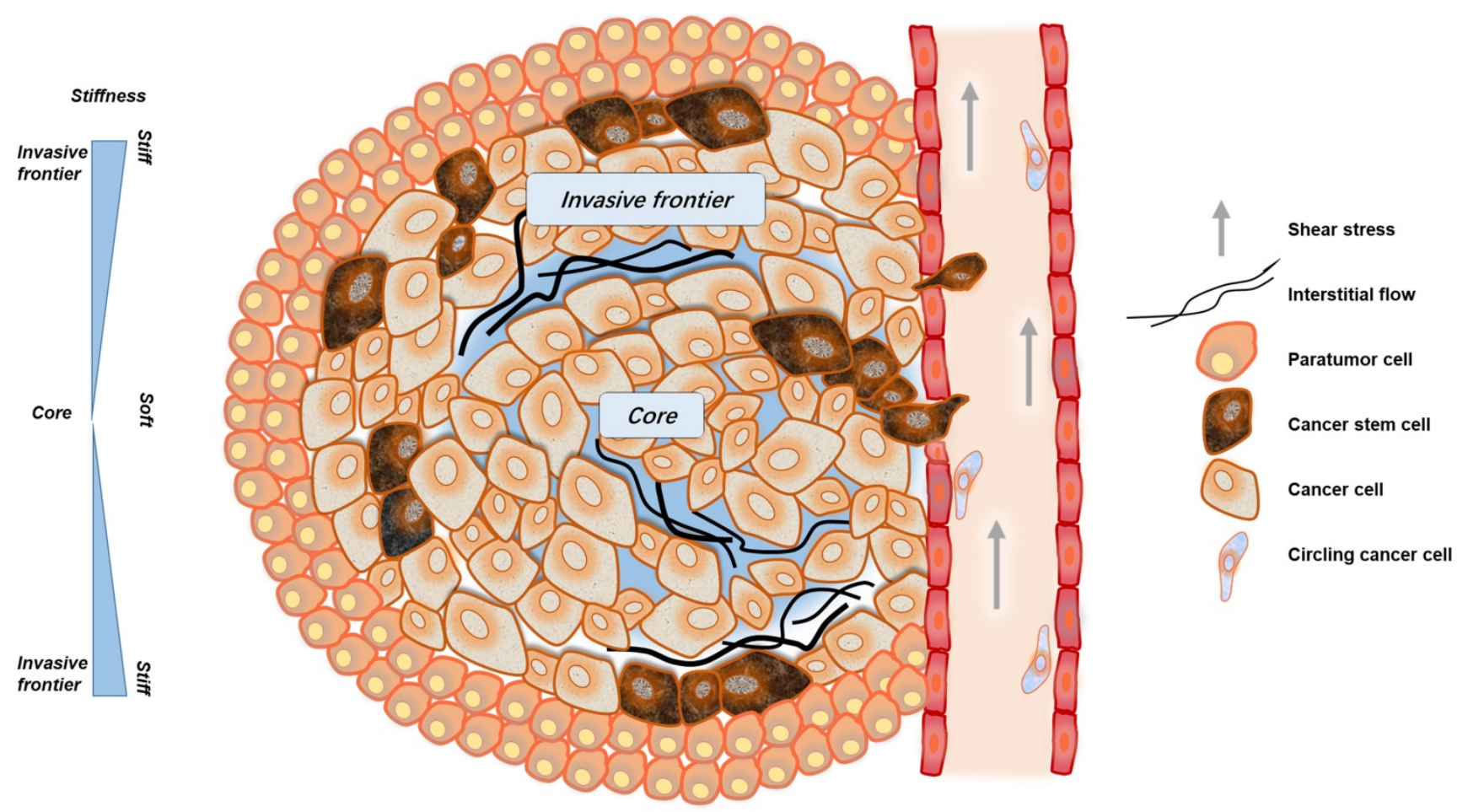

Figure 1. The mechanical microenvironment of cancer. CSCs are not uniformly distributed in cancer tissues. More CSCs are distributed in invasive frontiers to facilitate malignant metastasis. At the invasive frontier, CSCs are subjected to the forces of increased matrix stiffness, interstitial fluid pressure, and the tensile force of surrounding tissues. When CSCs enter the blood vessels, they are subjected to fluid shear forces generated by blood flow. These mechanical factors play important roles in maintaining the characteristics of CSCs.

In the circulatory system, cancer cells are subjected to fluid shear stress generated by blood flow, the fluid shear stress generated by the circulatory system is much greater than that generated by interstitial flow $[38,39]$. Only a small fraction of cancer cells, CSCs or circulating tumor cells (CTCs), can overcome or even exploit the effects of fluid shear, gradually escape the circulation and successfully arise metastatic tumors [40, 41] (Fig. 1).

\section{Compression and tension stress}

Solid stress is always present in solid cancer tissues. Owing to the epithelial frontier, all unregulated cancer cells grow in a limited space, which inevitably generates more solid stress in tumors compared with surrounding tissues [26]. The solid pressure within tumor reaches $45-120 \mathrm{~mm} \mathrm{Hg}$, so that exceeding the lymphatic or blood vessels pressure $(6-17 \mathrm{~mm} \mathrm{Hg}$ ) can cause the collapse of the tumor blood vessels [42].

Solid stresses caused by tumor growth can induce a variety of cellular behaviors. Mechanical stresses generated by cells and cellular structures play critical roles in epithelial homeostasis, driving diverse behaviors, such as mammary epithelial cell branching morphogenesis, epithelial-to-mesenchymal transition (EMT), and neoplastic progression [43]. The cancer cells in the invasion frontier are subjected to internal tension caused by irregular cancer cell growth, compressive stress from the external ECM, and surrounding paratumor tissue (Fig. 2). This can be thought of as filling a balloon with air, and as the interior expands, the border cells are pressed outward and stretched via interaction with their surroundings.

\section{Matrix stiffness and CSCs}

\section{Matrix stiffness and the stemness of CSCs}

With expansion, abnormal ECM accumulation results in increased stiffness of cancer tissue. Dozens of in vitro or in vivo experiments have demonstrated that cells are sensitive to reacting the stiffness of the substrate, regulating its migration, differentiation, and proliferation [30]. Engler et al. showed that mesenchymal stem cells (MSCs) can differentiate into specialized lineages with various stiffnesses of polyacrylamide gels (PA) gels. The results indicated that MSCs underwent primary neuronal differentiation on soft matrix stiffness $(0.1-1 \mathrm{kPa})$. Stiffer matrices (8-17 $\mathrm{kPa}$ ) lead MSCs to commit to myoblast differentiation, and a rigid matrix (25-40 $\mathrm{kPa}$ ) results in osteogenesis [44]. The differentiation potential of CSCs can also be regulated by matrix stiffness $[45,46]$. You et al. showed that hepatoma carcinoma cells presented high stemness on gels with up to $16 \mathrm{kPa}$ stiffness. Furthermore, mechanical signals were transmitted via the intracellular PI3K/Akt-mTOR-Sox2 pathway through the 

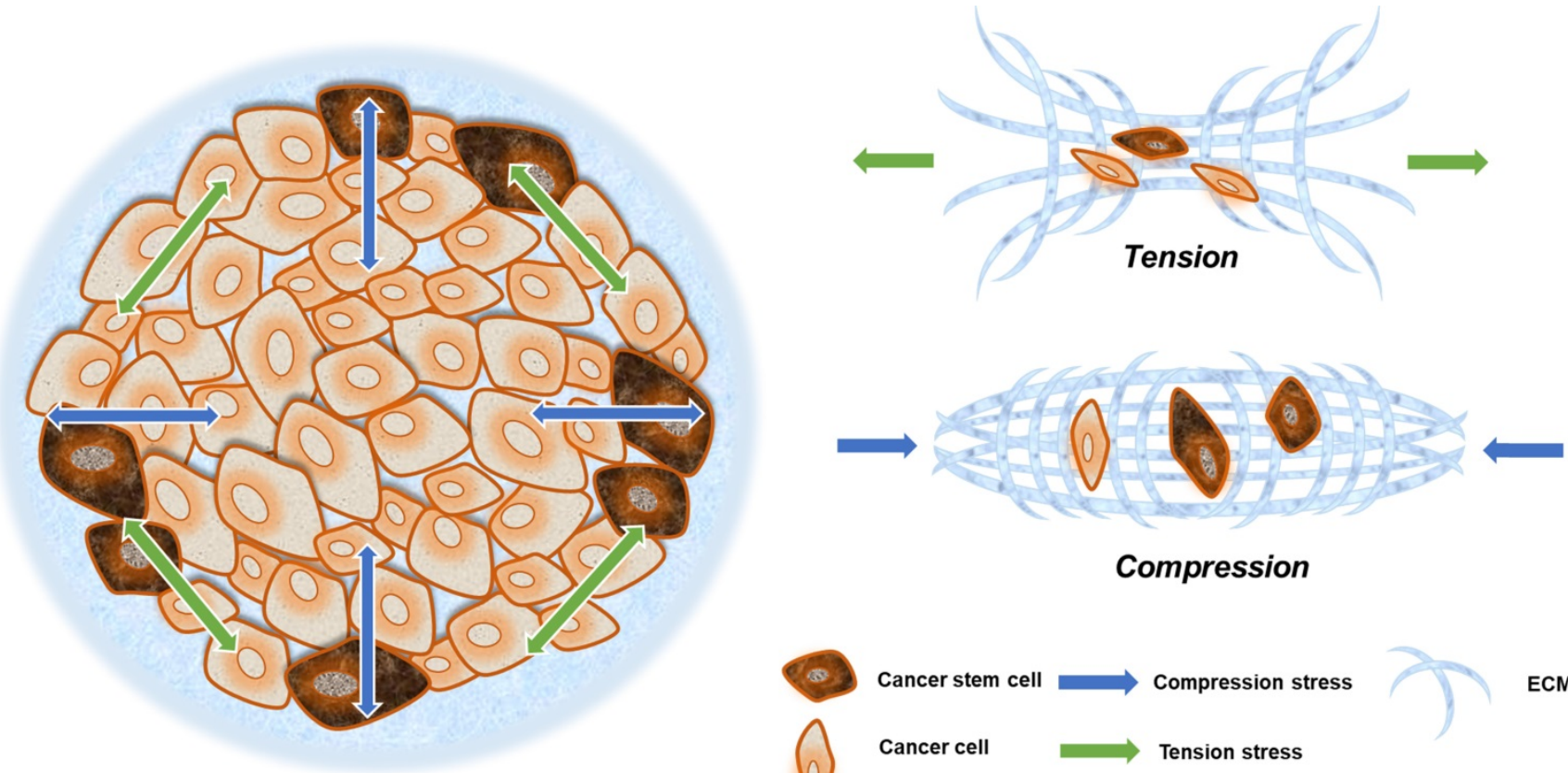

Cancer stem cell $\Rightarrow$ Compression stress

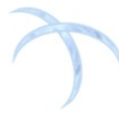

ECM

Figure 2. Compression and tension stress in a solid tumor. Neoplastic growth steadily increases tumor size, providing radial tension and axial compression to cancer cells. Cells at the invasive frontier are subjected to tension stress during cancer expansion, and that stress arrives from all directions (green arrow). What is more is that cells at the central area are subjected to compression stress during tissue expansion, and that stress mainly emanates from the invasive frontier directions (blue arrow).

transmembrane protein, integrin- $\beta 1$ (ITGB1), resulting in high expression of CD133 and epithelial cell adhesion molecule (EpCAM) [47]. ITGB1, also known as CD29, is a transmembrane receptor encoded by the ITGB1 gene in humans. Recent studies have shown that ITGB1 is not only related to mechanical factors but also closely related to CSCs and cancer differentiation [48]. Schrader et al. demonstrated that hepatoma stem cells were more abundant on softer gels $(1 \mathrm{kPa})$, a softer matrix can cause hepatoma cells to enter a quiescent and dormant state, increasing their stemness [49]. In addition, matrix stiffness significantly affects the stemness of lung cancer cells. The increased matrix stiffness (130-4020 Pa) dramatically elevates integrin- $\beta 1$ expression for transmitting the mechanical force and further activates the intracellular integrin-linked kinase (ILK)/PI3K/Akt signaling pathway [50]. In colon cancer, increased matrix stiffness (2.0-20.0 kPa) inhibits the expression of stemness markers, such as CD133 and acetaldehyde dehydrogenase 1 , by inhibiting the activation of yes-associated protein (YAP), PI3K, and Akt through integrin- $\beta 1$ [51]. CSCs derived from malignant melanoma have a better ability to maintain stem cell characteristics, exhibiting stronger self-renewal capacity, compared with well-differentiated melanoma cells in a soft matrix [52]. Besides, CSCs have low level of histone 3 lysine residue 9 (H3K9) methylation, which is unresponsive to matrix stiffness or applied forces [52].
Although several studies indicated that matrix stiffness significantly affects the differentiation and survival of cancer cells, several researchers have shown contradictory results. Various research models and measurement methods used to assess tissue stiffness may produce varied results in certain tissues. In addition, the selection of different references has led researchers to have varying standards for softness and stiffness. Cancer cells from different tissues have varied sensitivities and adaptabilities to mechanical signals. For example, hepatoma cells show higher stemness in stiff matrix, while melanoma cells express higher stem cell markers in the softer matrix [51-53]. To obtain more accurate experimental results, researchers' must be more cautious in the choice of stiffness.

In fact, the cells in the body locate in threedimensional (3D) environments, and the common methods of constructing different matrix stiffnesses with PA and other gels in the study usually provide two-dimensional (2D) matrix stiffness. By employing the $3 \mathrm{D}$ environment to simulate the mechanical environment of cancer cells in vivo, the precise information about the actual situation of cancer cells in the body is very necessary. Although some studies have shown that the stiffness of the matrix under $3 \mathrm{D}$ conditions affects the stemness of CSCs, the extant literature on the topic compared with the existing 2D conditions is far from sufficient [54].

Matrix stiffness is a key biomechanical force of the tumor microenvironment and correlates tightly 
with tumor progression. The mechanical receptors on the cell surface, such as integrins, CD44, and ion channels, can sense the change of ECM and activate the downstream key molecules, including FAK, ILK, RhoA, and YAP/TAZ. Some of the signals induce non-CSCs reprograming and transforming into CSCs through highly expressing Sox2, Oct- 4 and Nanog [47-53], finally leading to a poor prognosis. Although abnormal matrix stiffness increases cancer cell stemness, there might also be opportunities to take advantage of the abnormal stiffness by developing mechanosensitive treatment. One of the possible therapies is directly changing the matrix stiffness of the tumor by using metformin to reduce the tissue stiffness [55], targeting ECM components such as HA, or changing the secretion of cellular collagenase.

\section{Fluid Shear and CSCs}

\section{Interstitial fluid pressure in cancer}

Interstitial fluid and blood can produce fluid shear stress on cell surfaces under physiological conditions. However, the neovasculature are poorly functional with abnormal vessel network, and have a very high permeability compared to mature microvessels. Within tumors, the increasing number of lymphatic vessels around tumors, which is coupled with high IFP, will lead to an increased tumor fluid flux.

The flow rate of the interstitial flow is slow, and the velocity is just approximately $0.1-2 \mu \mathrm{m} / \mathrm{s}$, with the resultant fluid shear stress being approximately 0.01-0.2 Pa (0.1-2 dyne $\left./ \mathrm{cm}^{2}\right)$ [26]. Owing to advances in science and engineering, computational modeling is often used to carry out simulations and auxiliary experiments when evaluating interstitial flow $[40,56]$. The studies showed that cancer cells had sensitivity to microfluid shear stress in vitro and responded accordingly. Dong et al. showed that less fluid shear stress could affect the cytoskeleton and shape cell morphology [57]. IFP can increase the migration and invasion of cancer cells by activating CXCR4/CXCL12 and MEK/ERK signaling in hepatocellular carcinoma [58].

The IFP can maintain the biological properties of CSCs. Studies have shown that 0.02 dyne $/ \mathrm{cm}^{2}$ fluid shear could empower ovarian cancer cells with stronger stemness and EMT properties through microRNA-199a-3p or PI3K/Akt signaling pathways [59]. More importantly, the contribution of the interstitial flow is increasing osmolality by causing an increase in IFP [60]. IFP can also generate concentration gradients around cancer cells, providing the necessary growth factors and signaling molecules for CSCs [61].
IFP can activate the PI3K/Akt signaling pathway through surface receptors, such as integrins, to enhance the stemness of cancer cells. Additionally, rectifying abnormal IFP due to angiogenesis in the tumor microenvironment is a promising treatment option. For example, acting on VEGFs-VEGFR signaling pathway could reduce angiogenesis to weaken IFP, thereby improving the prognosis of patients [62].

\section{Blood shear stress and CSCs}

Compared to interstitial flow, blood flow has a faster velocity and larger coronary system. The flow of blood can produce greater fluid shear at 1-4 dyne $/ \mathrm{cm}^{2}$ in narrow vessels and $4-30$ dyne $/ \mathrm{cm}^{2}$ in larger vessels [39]. Before entering the peripheral blood circulation, cancer cells exhibit a pronounced dissemination ability after undergoing a series of changes; the biological behavior of cancer cells within the circulatory system is also affected by the action of hemodynamic forces [39]. Shear stress is the friction between blood flow and vascular endothelial cells, which regulate cell morphology and function. Fluid shear stress is critical for vascular remodeling and significantly regulates cancer cell metastasis and differentiation [63-65]. When enters into the blood circulation system, cancer cells face a completely different mechanical microenvironment [39]. Strong fluid shear stress is not suitable for cancer cell survival, although the harsh environment and immune mechanisms in the blood circulation remove most cancer cells, a small fraction of CSC/CTCs still initiate metastasis [66, 67]. Several lines of evidence suggest that a presumably small subset of CTCs also bear CSC characteristics based on their ability to give rise to tumors [68]. CTCs or CSCs have many similar characteristics, such as a high expression of cancer stem cell markers, CD90, CD44, and EpCAM, enhanced tumorigenic ability, pronounced colony forming ability, and greater EMT capacity [69]. Among them, EpCAM is one of the important markers used in clinical screening and identification of CTCs, and is commonly utilized in the study of CSCs and CTCs [70,71]. Therefore, several studies in recent years have proposed that the putative source of CTCs is CSCs [72].

Fluid shear stress can affect cancer cell migration through the ROCK signaling pathway, an upstream of the FAK and PI3K/Akt pathways, and finally impact the co-activation of the YAP/TAZ pathway [73]. $\mathrm{YAP} / \mathrm{TAZ}$, a key transcriptional coactivator in the Hippo pathway, has been reported in many recent studies to be associated with mechanical factors and can respond to a variety of mechanical stimuli [74]. Besides affecting the migration and deformation of 
cells, fluid shear stress promotes EMT in epithelial cells, a process that allow cancer cells to gain CSC phenotype $[75,76]$. Sun et al. showed that low shear stress inhibited sphere-forming ability, increased chemosensitivity, downregulated CSCs marker expression, and suppressed the in vivo tumorigenicity of liver CSCs [77]. Triantafillu et al. showed that fluid shear stress could promote the expression levels of CD24, EpCAM, Oct-4, Nanog, and other CSC markers, maintaining CSCs within circulatory system in breast cancer cell MCF-7, and this process was independent of EMT [78].

Eliminating CTCs/CSCs in blood stream is always an important strategy for the treatment of metastasis in the clinic. The mechanical signals provide possible treatment strategies for removing CTC/CSCs. For instance, YAP/TAZ might be a new potential target [73]. In addition, changing blood shear force may be a new method to eliminate CTCs/CSCs. At present, hemodynamic drugs that have been approved in the clinic, such as cardiovascular drugs and anticoagulants, might also influence tumor metastasis. An improved understanding of how shear stress influences CTC/CSCs at blood vessel could lead to the design of refined anti-metastatic approaches.

\section{Solid stress and CSCs}

Solid stress, as the major component of the biomechanical microenvironment, directly transmits mechanical signals to cells through the ECM, and indirectly affects cells by compressing blood vessels and lymph vessels [79].

Although many studies have shown that tensile and compressive stresses are potential assistors for cancer metastasis, none have directly indicated that CSCs are related to tensile and compressive stress. There is still inadequate explicit evidence to prove that tensile and compressive stress can affect the biological behavior of CSCs. Liang et al. suggested that compression significantly decreased pulposusderived MSC survival, differentiation, colony formation, and migration. Furthermore, compression loading could downregulate the expression of stem cell-related proteins and result in cell differentiation [80]. Gan et al. showed that less compression increased anabolic response, whereas more compression induced the catabolic response of MSCs by inhibiting the expression of transient receptor potential cation channel subfamily $\mathrm{V}$ member 4 (TRPV4) [81]. Osteocytes also respond to direct compressive stimuli. For instance, the differentiated murine osteoblastic cells MLO-A5, cultured in 3D scaffolds upregulated the expression of osteopontin and osteocalcin when exposed to a compressive loading regime consisting of $5 \%$ strain at $1 \mathrm{~Hz}-2 \mathrm{~h}$, approximately for three weeks [82]. Further investigation is thus needed to determine if mechanotransduction is maintained within cancer tissue when subjected to compression as well as if and how this prevalent mechanical stimulus influences the development of CSCs. Ultimately, research on the CSC mechanical microenvironment can provide more potential theoretical targets for therapeutic intervention of CSCs.

Although the relationship between stress and CSCs needs further research, adjusting the abnormal solid stress may improve response to various treatments, such as immunotherapy. The generation of solid stress is closely related to the ECM composition. Degrading the matrix composition or decreasing the degree of fibrosis will help reduce compression and tension stress. For example, losartan, an antagonist of angiotensin II receptor 1, degrades both collagen I and HA by blocking TGF- $\beta$ signal [83].

\section{Perspectives}

The mechanical factors play key roles in regulating the characteristics of CSCs. CSCs and normal stem cells often share similar surface markers and signaling pathways, which would restrict the design of treatment regimens [13]. In fact, it is challenging for new therapies to target CSCs without affecting normal stem cells. The abnormal biomechanical factors, which rarely exist in the harmonious microenvironment of normal stem cells, may provide new insights for CSC-targeted treatment. As such, discovering the relationship between biomechanical factors and CSCs will greatly enable the generation of novel research strategies to investigate the occurrence, development, and recurrence of cancers.

\section{Acknowledgements}

This work was supported by a grant from the National Natural Science Foundation of China (No. 31871413) and two from the Programs of Guangdong Science and Technology (2017B020230002 and 2016B030231001).

\section{Competing Interests}

The authors have declared that no competing interest exists.

\section{References}

1. Buja A, Lago L, Lago S, Vinelli A, Zanardo C, Baldo V. Marital status and stage of cancer at diagnosis: A systematic review. Eur J Cancer Care (Engl). 2018; 27: 1-16.

2. Smith RA, Andrews K, Brooks D, DeSantis CE, Fedewa SA, Lortet-Tieulent J, et al. Cancer screening in the United States, 2016: A review of current 
American Cancer Society guidelines and current issues in cancer screening. CA: a cancer journal for clinicians. 2016; 66: 96-114.

3. Teng YD, Wang L, Kabatas S, Ulrich H, Zafonte RD. Cancer Stem Cells or Tumor Survival Cells? Stem cells and development. 2018; 27: 1466-78.

4. Medema JP. Cancer stem cells: the challenges ahead. Nature cell biology. 2013; 15: 338-44.

5. Lapidot T, Sirard C, Vormoor J, Murdoch B, Hoang T, Caceres-Cortes J, et al. A cell initiating human acute myeloid leukaemia after transplantation into SCID mice. Nature. 1994; 367: 645-8.

6. Klarmann GJ, Hurt EM, Mathews LA, Zhang X, Duhagon MA, Mistree T, et al. Invasive prostate cancer cells are tumor initiating cells that have a stem cell-like genomic signature. Clinical \& experimental metastasis. 2009; 26: 433-46.

7. Yuan X, Curtin J, Xiong Y, Liu G, Waschsmann-Hogiu S, Farkas DL, et al. Isolation of cancer stem cells from adult glioblastoma multiforme. Oncogene. 2004; 23: 9392-400

8. Cao L, Zhou Y, Zhai B, Liao J, Xu W, Zhang R, et al. Sphere-forming cell subpopulations with cancer stem cell properties in human hepatoma cell lines. BMC gastroenterology. 2011; 71: 1-11.

9. Ma S, Chan KW, Hu L, Lee TK, Wo JY, Ng IO, et al. Identification and characterization of tumorigenic liver cancer stem/progenitor cells. Gastroenterology. 2007; 132: 2542-56.

10. Ponti D, Costa A, Zaffaroni N, Pratesi G, Petrangolini G, Coradini D, et al. Isolation and in vitro propagation of tumorigenic breast cancer cells with stem/progenitor cell properties. Cancer research. 2005; 65: 5506-11.

11. Lagadec C, Vlashi E, Della Donna L, Dekmezian C, Pajonk F. Radiation-induced reprogramming of breast cancer cells. Stem Cells. 2012; 30: 833-44.

12. He K, Xu T, Xu Y, Ring A, Kahn M, Goldkorn A. Cancer cells acquire a drug resistant, highly tumorigenic, cancer stem-like phenotype through modulation of the PI3K/Akt/beta-catenin/CBP pathway. International journal of cancer. 2014; 134: 43-54

13. Bu Y, Cao D. The origin of cancer stem cells. Front Biosci (Schol Ed). 2012; 4: 819-30.

14. Gkountela S, Aceto N. Stem-like features of cancer cells on their way to metastasis. Biology direct. 2016; 33: 1-14.

15. Bregenzer ME, Horst EN, Mehta P, Novak CM, Repetto T, Mehta G. The Role of Cancer Stem Cells and Mechanical Forces in Ovarian Cancer Metastasis. Cancers (Basel). 2019; 11: 1-22

16. Park TS, Donnenberg VS, Donnenberg AD, Zambidis ET, Zimmerlin L. Dynamic Interactions Between Cancer Stem Cells and Their Stromal Partners. Current pathobiology reports. 2014; 2: 41-52.

17. Plaks V, Kong N, Werb Z. The cancer stem cell niche: how essential is the niche in regulating stemness of tumor cells? Cell stem cell. 2015; 16: 225-38.

18. Vining $\mathrm{KH}$, Mooney DJ. Mechanical forces direct stem cell behaviour in development and regeneration. Nat Rev Mol Cell Biol. 2017; 18: 728-42.

19. Steward AJ, Kelly DJ. Mechanical regulation of mesenchymal stem cell differentiation. Journal of anatomy. 2015; 227: 717-31.

20. Nathan SS, DiResta GR, Casas-Ganem JE, Hoang BH, Sowers R, Yang R, et al. Elevated physiologic tumor pressure promotes proliferation and chemosensitivity in human osteosarcoma. Clinical cancer research: an official journal of the American Association for Cancer Research. 2005; 11: 2389-97.

21. Pisanu ME, Noto A, De Vitis C, Masiello MG, Coluccia P, Proietti S, et al. Lung cancer stem cell lose their stemness default state after exposure to microgravity. BioMed research international. 2014; 2014: 470253.

22. Lu D, Luo C, Zhang C, Li Z, Long M. Differential regulation of morphology and stemness of mouse embryonic stem cells by substrate stiffness and topography. Biomaterials. 2014; 35: 3945-55.

23. Hao J, Zhang Y, Ye R, Zheng Y, Zhao Z, Li J. Mechanotransduction in cancer stem cells. Cell biology international. 2013; 37: 888-91.

24. Northey JJ, Przybyla L, Weaver VM. Tissue Force Programs Cell Fate and Tumor Aggression. Cancer Discov. 2017; 7: 1224-37.

25. Mohammadi H, Sahai E. Mechanisms and impact of altered tumour mechanics. Nature cell biology. 2018; 20: 766-74.

26. Shieh AC. Biomechanical forces shape the tumor microenvironment. Annals of biomedical engineering. 2011; 39: 1379-89.

27. Kutikhin AG, Sinitsky MY, Yuzhalin AE, Velikanova EA. Shear stress: An essential driver of endothelial progenitor cells. J Mol Cell Cardiol. 2018; 118: 46-69.

28. Huang Q, Hu X, He W, Zhao $Y$, Hao $S, W u$ Q, et al. Fluid shear stress and tumor metastasis. Am J Cancer Res. 2018; 8: 763-77.

29. Georges PC, Hui JJ, Gombos Z, McCormick ME, Wang AY, Uemura M, et al. Increased stiffness of the rat liver precedes matrix deposition: implications for fibrosis. American journal of physiology Gastrointestinal and liver physiology. 2007; 293: G1147-54.

30. Chim LK, Mikos AG. Biomechanical forces in tissue engineered tumor models. Current opinion in biomedical engineering. 2018; 6: 42-50.

31. de Ledinghen V, Wong VW, Vergniol J, Wong GL, Foucher J, Chu SH, et al. Diagnosis of liver fibrosis and cirrhosis using liver stiffness measurement: comparison between M and XL probe of FibroScan(R). Journal of hepatology. 2012; 56: 833-9.

32. Cortini M, Avnet S, Baldini N. Mesenchymal stroma: Role in osteosarcoma progression. Cancer Lett. 2017; 405: 90-9.

33. Muller DA, Silvan U. On the biomechanical properties of osteosarcoma cells and their environment. Int J Dev Biol. 2019; 63: 1-8.
34. Plodinec M, Loparic M, Monnier CA, Obermann EC, Zanetti-Dallenbach $\mathrm{R}$, Oertle $\mathrm{P}$, et al. The nanomechanical signature of breast cancer. Nat Nanotechnol. 2012; 7: 757-65.

35. Tamura R, Tanaka T, Akasaki Y, Murayama Y, Yoshida K, Sasaki H. The role of vascular endothelial growth factor in the hypoxic and immunosuppressive tumor microenvironment: perspectives for therapeutic implications. Med Oncol. 2019; 37: 2.

36. Lunt SJ, Fyles A, Hill RP, Milosevic M. Interstitial fluid pressure in tumors: therapeutic barrier and biomarker of angiogenesis. Future oncology (London, England). 2008; 4: 793-802.

37. Mori T, Nishi W, Yamada T, Motooka Y, Ikeda K, Shiraishi K, et al. Interstitial fluid pressure of thymic epithelial tumours. Interact Cardiovasc Thorac Surg. 2017; 25: 167-72

38. Weinbaum S, Cowin SC, Zeng Y. A model for the excitation of osteocytes by mechanical loading-induced bone fluid shear stresses. Journal of biomechanics. 1994; 27: 339-60.

39. Weinbaum S, Duan $Y$, Satlin LM, Wang $T$, Weinstein AM. Mechanotransduction in the renal tubule. American journal of physiology Renal physiology. 2010; 299: F1220-36

40. Vilanova G, Bures M, Colominas I, Gomez H. Computational modelling suggests complex interactions between interstitial flow and tumour angiogenesis. J R Soc Interface. 2018; 15: 20180415.

41. Shieh AC, Swartz MA. Regulation of tumor invasion by interstitial fluid flow. Phys Biol. 2011; 8: 015012.

42. Helmlinger G, Netti PA, Lichtenbeld HC, Melder RJ, Jain RK. Solid stress inhibits the growth of multicellular tumor spheroids. Nat Biotechnol. 1997; 15: 778-83.

43. Northcott JM, Dean IS, Mouw JK, Weaver VM. Feeling Stress: The Mechanics of Cancer Progression and Aggression. Frontiers in cell and developmental biology. 2018; 6: 17

44. Engler AJ, Sen S, Sweeney HL, Discher DE. Matrix elasticity directs stem cell lineage specification. Cell. 2006; 126: 677-89.

45. Tang X, Kuhlenschmidt TB, Zhou J, Bell P, Wang F, Kuhlenschmidt MS, et al. Mechanical force affects expression of an in vitro metastasis-like phenotype in HCT-8 cells. Biophysical journal. 2010; 99: 2460-9.

46. Avnet S, Cortini M. Role of Pericellular Matrix in the Regulation of Cancer Stemness. Stem cell reviews. 2016; 12: 464-75.

47. You $Y$, Zheng $\mathrm{Q}$, Dong $\mathrm{Y}$, Xie $\mathrm{X}$, Wang $\mathrm{Y}$, Wu $\mathrm{S}$, et al. Matrix stiffness-mediated effects on stemness characteristics occurring in HCC cells. Oncotarget. 2016; 7: 32221-31.

48. Gupta RK, Johansson S. beta1 integrins restrict the growth of foci and spheroids. Histochemistry and cell biology. 2012; 138: 881-94.

49. Schrader J, Gordon-Walker TT, Aucott RL, van Deemter M, Quaas A, Walsh S, et al. Matrix stiffness modulates proliferation, chemotherapeutic response, and dormancy in hepatocellular carcinoma cells. Hepatology (Baltimore, Md). 2011; 53: 1192-205.

50. Pang MF, Siedlik MJ, Han S, Stallings-Mann M, Radisky DC, Nelson CM. Tissue Stiffness and Hypoxia Modulate the Integrin-Linked Kinase ILK to Control Breast Cancer Stem-like Cells. Cancer research. 2016; 76: 5277-87.

51. Tan F, Huang Y, Pei Q, Liu H, Pei H, Zhu H. Matrix stiffness mediates stemness characteristics via activating the Yes-associated protein in colorectal cancer cells. Journal of cellular biochemistry. 2018; 120: 2213-25.

52. Tan Y, Tajik A, Chen J, Jia Q, Chowdhury F, Wang L, et al. Matrix softness regulates plasticity of tumour-repopulating cells via H3K9 demethylation and Sox2 expression. Nature communications. 2014; 5: 4619

53. Liu J, Tan Y, Zhang H, Zhang Y, Xu P, Chen J, et al. Soft fibrin gels promote selection and growth of tumorigenic cells. Nature materials. 2012; 11: 734-41.

54. Wang X, Dai X, Zhang X, Li X, Xu T, Lan Q. Enrichment of glioma stem cell-like cells on 3D porous scaffolds composed of different extracellular matrix. Biochemical and biophysical research communications. 2018; 498: 1052-7.

55. Incio J, Suboj P, Chin SM, Vardam-Kaur T, Liu H, Hato T, et al. Metformin Reduces Desmoplasia in Pancreatic Cancer by Reprogramming Stellate Cells and Tumor-Associated Macrophages. PLoS ONE. 2015; 10: e0141392.

56. Mitchell MJ, King MR. Computational and experimental models of cancer cell response to fluid shear stress. Frontiers in oncology. 2013; 3: 44

57. Dong Y, Skelley AM, Merdek KD, Sprott KM, Jiang C, Pierceall WE, et al. Microfluidics and circulating tumor cells. The Journal of molecular diagnostics: JMD. 2013; 15: 149-57.

58. Shah AD, Bouchard MJ, Shieh AC. Interstitial Fluid Flow Increases Hepatocellular Carcinoma Cell Invasion through CXCR4/CXCL12 and MEK/ERK Signaling. PLoS ONE. 2015; 10: e0142337

59. Ip CK, Li SS, Tang MY, Sy SK, Ren Y, Shum HC, et al. Stemness and chemoresistance in epithelial ovarian carcinoma cells under shear stress. Scientific Reports. 2016; 6: 26788

60. Shah MM, Mandiga P. Physiology, Plasma Osmolality and Oncotic Pressure. Treasure Island, FJ: StatPearls Publishing; 2020.

61. V.S. Shirure, A. Lezia, A. Tao, L.F. Alonzo, S.C. George, Low levels of physiological interstitial flow eliminate morphogen gradients and guide angiogenesis, Angiogenesis, 2017; 20: 493-504.

62. Fukumura D, Kloepper J, Amoozgar Z, Duda DG, Jain RK. Enhancing cancer immunotherapy using antiangiogenics: opportunities and challenges. Nat Rev Clin Oncol. 2018; 15: 325-40. 
63. Becquart P, Cruel M, Hoc T, Sudre L, Pernelle K, Bizios R, et al. Human mesenchymal stem cell responses to hydrostatic pressure and shear stress. European Cells and Materials. 2016; 31: 160-73.

64. Materials. 2016; 31: 160-73.64. Hu K, Sun H, Gui B, Sui C. TRPV4 functions in flow shear stress induced early osteogenic differentiation of human bone marrow mesenchymal stem cells. Biomed Pharmacother. 2017; 91: 841-8.

65. Rashidi H, Alhaque S, Szkolnicka D, Flint O, Hay DC. Fluid shear stress modulation of hepatocyte-like cell function. Arch Toxicol. 2016; 90: 1757-61.

66. Paoletti C, Hayes DF. Circulating Tumor Cells. Advances in experimental medicine and biology. 2016; 882: 235-58

67. Syrigos K, Fiste O, Charpidou A, Grapsa D. Circulating tumor cells count as a predictor of survival in lung cancer. Critical reviews in oncology/hematology. 2018; 125: 60-8.

68. Scholch S, Garcia SA, Iwata N, Niemietz T, Betzler AM, Nanduri LK, et al. Circulating tumor cells exhibit stem cell characteristics in an orthotopic mouse model of colorectal cancer. Oncotarget. 2016; 7: 27232-42.

69. Tinhofer I, Saki M, Niehr F, Keilholz U, Budach V. Cancer stem cell characteristics of circulating tumor cells. International journal of radiation biology. 2014; 90: 622-7.

70. Kimura $\mathrm{O}$, Takahashi $\mathrm{T}$, Ishii $\mathrm{N}$, Inoue $\mathrm{Y}$, Ueno $\mathrm{Y}$, Kogure $\mathrm{T}$, et al. Characterization of the epithelial cell adhesion molecule (EpCAM)+ cell population in hepatocellular carcinoma cell lines. Cancer science. 2010; 101: 2145-55.

71. Yamashita T, Ji J, Budhu A, Forgues M, Yang W, Wang HY, et al EpCAM-positive hepatocellular carcinoma cells are tumor-initiating cells with stem/progenitor cell features. Gastroenterology. 2009; 136: 1012-24.

72. Yang MH, Imrali A, Heeschen C. Circulating cancer stem cells: the importance to select. Chinese journal of cancer research $=$ Chung-kuo yen cheng yen chiu. 2015; 27: 437-49.

73. Lee HJ, Diaz MF, Price KM, Ozuna JA, Zhang S, Sevick-Muraca EM, et al. Fluid shear stress activates YAP1 to promote cancer cell motility. Nature communications. 2017; 8: 14122

74. Dupont S. Role of YAP/TAZ in cell-matrix adhesion-mediated signalling and mechanotransduction. Experimental cell research. 2016; 343: 42-53.

75. Mitra A, Mishra L, Li S. EMT, CTCs and CSCs in tumor relapse and drug-resistance. Oncotarget. 2015; 6: 10697-711.

76. Liu S, Zhou F, Shen Y, Zhang Y, Yin H, Zeng Y, et al. Fluid shear stress induces epithelial-mesenchymal transition (EMT) in Hep-2 cells. Oncotarget. 2016; 7: 32876-92.

77. Sun J, Luo Q, Liu L, Song G. Low-level shear stress induces differentiation of liver cancer stem cells via the Wnt/beta-catenin signalling pathway. Experimental cell research. 2018; 375:90-96.

78. Triantafillu UL, Park S, Klaassen NL, Raddatz AD, Kim Y. Fluid shear stress induces cancer stem cell-like phenotype in MCF7 breast cancer cell line without inducing epithelial to mesenchymal transition. International journal of oncology. 2017; 50: 993-1001.

79. Stylianopoulos T. The Solid Mechanics of Cancer and Strategies for Improved Therapy. J Biomech Eng. 2017; 139: 1216-30.

80. Liang H, Chen S, Huang D, Deng X, Ma K, Shao Z. Effect of Compression Loading on Human Nucleus Pulposus-Derived Mesenchymal Stem Cells. Stem cells international. 2018; 2018: 1481243

81. Gan Y, Tu B, Li P, Ye J, Zhao C, Luo L, et al. Low Magnitude of Compression Enhances Biosynthesis of Mesenchymal Stem Cells towards Nucleus Pulposus Cells via the TRPV4-Dependent Pathway. Stem cells international. 2018; 2018: 7061898.

82. Sittichockechaiwut A, Scutt AM, Ryan AJ, Bonewald LF, Reilly GC. Use of rapidly mineralising osteoblasts and short periods of mechanical loading to accelerate matrix maturation in 3D scaffolds. Bone. 2009; 44: 822-9.

83. Chauhan VP, Martin JD, Liu H, Lacorre DA, Jain SR, Kozin SV, et al. Angiotensin inhibition enhances drug delivery and potentiates chemotherapy by decompressing tumour blood vessels. Nature communications. 2013; 4: 2516.

84. Sun J, Luo Q, Liu L, Song G. Low-level shear stress promotes migration of liver cancer stem cells via the FAK-ERK1/2 signalling pathway. Cancer Lett. 2018; $427: 1-8$

85. Delarue M, Montel F, Vignjevic D, Prost J, Joanny JF, Cappello G. Compressive stress inhibits proliferation in tumor spheroids through a volume limitation. Biophysical journal. 2014; 107: 1821-8. 